\title{
An Experimental and Mathematical investigation of optimal tilt angle and effects of reflectors on PV energy production
}

\author{
Yathin Krishna ${ }^{1,2 *}$, Shashikantha Karinka $^{3}$, Mohd Faizal Fauzan ${ }^{1,4 *}$, Prashanth Pai \\ Manihalla ${ }^{2}$ \\ ${ }^{1}$ School of Computer Science and Engineering, Taylor's University, 47500 Subang Jaya, Selangor, \\ Malaysia. \\ ${ }^{2} \mathrm{P}$ A College of Engineering, Nadupadav, Mangalore, Karnataka, India 574153. \\ ${ }^{3}$ NMAM Institute of Technology, Nitte, Karkala Taluk, Udupi District, Karnataka, India 574110. \\ ${ }^{4}$ Solar Energy Research Institute, Universiti Kebangsaan Malaysia, 43600 Bangi, Selangor, Malaysia.
}

\begin{abstract}
The performance of the solar photovoltaic panels relies on its direction and tilt angle with respect to the horizontal to obtain better conversion efficiency. The tilt angle of the PV panel needs to be in proper location and position to obtain maximum power output from photovoltaics. The optimum tilt angle is generally calculated based on global, diffused, and direct radiation on the horizontal surface. This study focuses on the concept of the optimal tilt angle that improves the performance of the PV panel. The paper discusses the MATLAB mathematical modelling and experimental validation conducted at Nitte, India to determine the optimal tilt angle of PV panels of the region for maximum solar radiation. The investigation also includes the effect of three different types of reflectors on the PV panel for the obtained optimal tilt angle. The experimental results show that to get the optimum power output, the tilt angle needs to be changed every month. Hence monthly optimal tilt must be chosen for optimum power output. The results showed a PV panel with a focused mirror reflector produced higher power output compared to aluminum and stainless-steel reflectors.
\end{abstract}

\section{Introduction}

With the fast phase research and development of solar PV (photovoltaic), power generation using solar PV systems plays an important role in fulfilling energy demands in the future by attaining grid parity [1]. It is said that the amount of solar energy received in one hour can satisfy the energy demand of the earth's population for an entire year. Earth's rotation around its axis and re ${ }^{1}$ volution around the sun affects the amount of radiation that reaches the earth's surface. Solar radiation is converted to heat through solar thermal technology and to electricity through Photovoltaic cells. Photovoltaic technology is becoming one of the promising applications with several advancements in technology and has the potential to meet most of the energy demands. Extensive efforts are being made to

*Corresponding authors: yathinkrishna@sd.taylors.edu.my; drfaizalfauzan@gmail.com 
increase the performance of PV panels and at the same time to reduce the cost of electronic devices used in the PV systems [2]. One of the efficient ways to improve the performance of the PV panel is by collecting maximum radiation which is possible by tracking the sun appropriately. But solar trackers are economical only when employed in large-scale production. Several research works have been carried out to obtain more radiation by using an optimal tilt angle in efficient ways. In Northern Hemisphere, generally, the PV panels are south facing and the optimum tilt angle depends on the day of the year and latitude of the location [3]. Hence in most of the places, the optimal tilt is taken equal to the latitude of the location. Nevertheless, the tilt angle differs throughout the year due to earth rotation and revolution. Hence tilt angle varies for different seasons of the year, i.e., in winter the sun is at the lowest path of the sky and requires higher tilt angles whereas during summer the sun is at the uppermost path of the sky and requires lower tilt angles. Generally, for such cases, the tilt angle for winter is taken as latitude $+15^{\circ}$ and for summer the tilt angle is latitude- $15^{\circ}$ [4]. However, this thumb rule does not match in reality for all locations due to local weather conditions and other reasons. Several simulation models and experiments have been carried out to increase the power output of the PV panels by optimizing the tilt angle. Asad Ullah et al. proposed a model to schedule four adjustments for panel tilt in a year to obtain an optimum tilt angle in the city of Lahore. The adjustments in the tilt angle provided a $\sim 6.6 \%$ increase in annual energy generation compared to fixed-tilt PV panels [5]. Mian Guo et al. [6] determined the optimum tilt angle using HS (Harmony search) meta-heuristic algorithm, the results of the investigation demonstrated that the tilt angle should be changed at least once a month, and the orientation of the PV panels should be facing south in selected cities of China.

Kaddoura et al. [7] investigated the optimal tilt angle for various cities in Saudi Arabia using MATLAB simulations and experimental setup, by obtaining the horizontal radiation data from NASA. The results revealed that $95.5 \%$ of solar radiation could be harvested just by adjusting tilt angles six times per year which could be attained with daily PV panel adjustments. Appelbaum [8] conducted an experimental investigation on the annual incident radiation on a solar field comprising of bifacial solar panels. The panels which are placed at optimal tilt angle and panels which are installed vertically and placed in east west direction is compared. The results showed that the panels with optimal tilt angle produced $32 \%$ more energy compared to vertically placed panels. Jain et al. [9] investigated optimal tilt angles for PV panels in India and based on annual energy gain, agreed on the fact that the monthly tilt angle adjustments are better than any other arrangements.

Also, many researchers investigated obtaining maximum power output from the PV panels by using reflectors at the optimum tilt angle. Tabor [10] used the mirror for the first time in 1958 to increase the concentration of solar radiation on solar collectors. Prashanth Malik et al. [11] studied the performance of PV-mirror reflector system placed at optimum tilt angle in Himachal Pradesh India, the results showed that the power output got enhanced by $10-19.84 \%$ in summer and $10-13.23 \%$ during the winter compared to PV panel without any reflectors attached. Kabeel et al. [12] investigated the performance of PV panels by using mirror reflectors to enhance power output, the experimental results showed that the power output increased by involving reflectors to concentrate solar radiation on PV panels. From the literature it is evident that the optimal tilt for a year, for a particular location, is not equivalent to the latitude of the location most of the times. Due to variation in tilt angle throughout the year because of the varied sun's path during different seasons, it is difficult to capture maximum sun's radiation with fixed tilt angle. Therefore, by altering the tilt angle monthly, seasonally, or bi-annually will enhance the output power of PV panel by substantial amount.

Considering all the above facts, the main objective of the present study is to find the optimal tilt angle for south-facing panels at Nitte, India. Also, in this study mirror reflector, aluminum sheet reflector, and stainless-steel reflector are used to identify their impact on the 
power output of solar panels at optimal tilt angles. This experimental study also focuses on determining the relation between the optimal tilt and latitude for various seasons of the year.

\section{Methodology}

India has a great potential to generate electricity from solar energy because on average the country has about 300-330 sunny days and an average of 1500-2000 sunshine hours based on location [13]. To determine the influence of the tilt angle on the output power of the PV panel, an experimental study has been carried out in Solar Energy Park, NMAM Institute of Technology at Nitte in India, in the year 2019-20. The site is located at a latitude of $13.18^{\circ}$, the longitude of $74.93^{\circ}$, and at an altitude of 20 meters above sea level. The solar radiation measurements for all the places are frequently not available. Hence mathematical relations linking the global and diffuse radiation values have been determined by several researchers [14]. The amount of solar radiation received by a photovoltaic panel mainly depends on the tilt angle, geographic position, local weather conditions, and time of use. Sun angles are mainly dependent on the day, the latitude of the location, and the movement of the sun [15]. The step-wise method of determining the daily radiation falling on a tilted surface $\mathrm{H}_{T}$ is as follows. The declination ' $\delta$ ' is the angle made by joining the centers of sun and earth with its projection on the equatorial plane as shown in Equation (1) [14].

$$
\delta=23.45 \sin \left[\frac{360}{365}(284+\mathrm{n})\right]
$$

Where $\mathrm{n}$ is the day of the year.

The sunrise or sunset hour $\omega_{\text {st }}$ (in degrees) and day length $S_{\max }$ (in Hours) on a tilted surface for south-facing panels $\left(\gamma=0^{\circ}\right)$ is determined by the Equations (2) and (3). The surface azimuth angle ' $\gamma$ ' is the angle made in the horizontal plane between the line due to the south and the projection of the normal to the surface on the horizontal plane $[6,14]$.

$$
\begin{aligned}
& \omega_{\mathrm{st}}=\operatorname{Cos}^{-1}[-\tan (\phi-\beta) \tan \delta] \\
& \mathrm{S}_{\max }=\frac{2}{15} \operatorname{Cos}^{-1}[-\tan (\phi-\beta) \tan \delta]
\end{aligned}
$$

Where, $\phi$ is the latitude of location in Degrees.

$\beta$ is the angle at which the panel is tilted in Degrees.

The monthly average of daily extra-terrestrial radiation which would fall on a tilted surface at a particular location is given by $\mathrm{H}_{\mathrm{o}}[6,14]$.

$$
H_{o}=\frac{24}{\pi} I_{s c}\left[1+0.033 \cos \frac{360 n}{365}\right]\left[\omega_{s t} \sin \phi \sin \delta+\cos \phi \cos \delta \sin \omega_{s t}\right]
$$

To make the calculations simpler, Klein [16] has determined the representative days for each month during which the extra-terrestrial radiation is almost equal to the value of a monthly mean as represented in Table 1 . The monthly average of the daily global radiation on a horizontal surface at a location is represented as $\mathrm{H}_{\mathrm{g}}\left(\mathrm{kJ} / \mathrm{m}^{2}\right.$-day), where a and $\mathrm{b}$ are 
constants obtained by fitting data. The values of $\mathrm{a}$ and $\mathrm{b}$ for the Mangalore region are given as 0.27 and 0.43 respectively [14].

Table 1: Sunshine hours and representative days for the entire year

\begin{tabular}{|l|c|c|c|}
\hline Month & Sunshine hours 'S' & Representative day & n \\
\hline Jan & 9.6 & 17 & 17 \\
\hline Feb & 10.28 & 16 & 47 \\
\hline Mar & 9.5 & 16 & 75 \\
\hline Apr & 9.6 & 15 & 105 \\
\hline May & 8.9 & 15 & 135 \\
\hline Jun & 4.2 & 11 & 162 \\
\hline Jul & 2.5 & 17 & 198 \\
\hline Aug & 4.3 & 16 & 228 \\
\hline Sept & 5.7 & 15 & 258 \\
\hline Oct & 7.3 & 15 & 288 \\
\hline Nov & 8.6 & 14 & 318 \\
\hline Dec & 9 & 10 & 344 \\
\hline
\end{tabular}

$$
\mathrm{H}_{\mathrm{g}}=\mathrm{H}_{\mathrm{o}}\left[\mathrm{a}+\mathrm{b}\left(\frac{\mathrm{S}}{\mathrm{S}_{\text {max }}}\right)\right]
$$

$\mathrm{H}_{\mathrm{g}}$ is related to the Clearness index ' $\mathrm{K}_{\mathrm{T}}$ ' which is the amount of extraterrestrial solar radiation that passes through the panel surface and is represented in equation (6) [14],

$$
\mathrm{K}_{\mathrm{T}}=\frac{\mathrm{H}_{\mathrm{g}}}{\mathrm{H}_{\mathrm{o}}}
$$

The correlation between global radiation ' $\mathrm{Hg}$ ' and diffuse radiation ' $\mathrm{H}_{\mathrm{d}}$ ' Indian data is expressed in equation (7) [14]. This equation is valid for $0.3<\mathrm{K}_{\mathrm{T}}<0.7$. In the other case, when the value of $\mathrm{K}_{\mathrm{T}}$ is not within the mentioned limit the standard expression by Liu \& Jordan [17] can be used [14].

$$
\mathrm{H}_{\mathrm{d}}=\mathrm{H}_{\mathrm{g}}\left[1.411-1.696 \frac{\mathrm{H}_{\mathrm{g}}}{\mathrm{H}_{\mathrm{o}}}\right]
$$

Where, $\mathrm{H}_{\mathrm{d}}$ is the monthly average of the daily diffuse radiation $\left(\mathrm{kJ} / \mathrm{m}^{2}\right.$-day).

The solar radiation passing through the atmosphere undergoes scattering and absorption due which the direction of radiation changes. The radiation that reaches the surface without scattering and absorption is known as beam radiation. The radiation that reaches the surface after under-going scattering and absorption is known as diffuse radiation. The radiation that gets reflected by the ground and other objects on the ground is known as reflected radiation. Thus, the total radiation that is received on the earth's surface is the sum of beam radiation, diffuse radiation, and reflected radiation. The beam radiation $\left(\mathrm{R}_{\mathrm{b}}\right)$, diffuse radiation $\left(\mathrm{R}_{\mathrm{d}}\right)$ and reflected radiation $\left(R_{r}\right)$ falling on the tilted surface is expressed in Equations (8)-(10) respectively. For India, the value of diffuse reflectance, ' $\rho$ ' is taken as 0.2 [14]. 


$$
\begin{aligned}
& \mathrm{R}_{\mathrm{b}}=\frac{\omega_{\mathrm{st}} \sin \delta \sin (\phi-\beta)+\cos \delta \sin \omega_{\mathrm{st}} \cos (\phi-\beta)}{\omega_{\mathrm{st}} \sin \phi \sin \delta+\cos \phi \cos \delta \sin \omega_{\mathrm{st}}} \\
& \mathrm{R}_{\mathrm{d}}=\frac{1+\cos \beta}{2} \\
& \mathrm{R}_{\mathrm{r}}=\rho\left[\frac{1-\cos \beta}{2}\right]
\end{aligned}
$$

The daily radiation falling on tilted surface ' $\mathrm{H}_{\mathrm{T}}$ ' (in $\mathrm{kJ} / \mathrm{m}^{2}$-day), for south-facing panel is expressed in Equation (11) [14].

$$
\mathrm{H}_{\mathrm{T}}=\mathrm{H}_{\mathrm{g}}\left[\left(1-\frac{\mathrm{H}_{\mathrm{d}}}{\mathrm{H}_{\mathrm{g}}}\right) \mathrm{R}_{\mathrm{b}}+\frac{\mathrm{H}_{\mathrm{d}}}{\mathrm{H}_{\mathrm{g}}} \mathrm{R}_{\mathrm{d}}+\mathrm{R}_{\mathrm{r}}\right]
$$

To determine the optimal tilt angle for each month of the year, a MATLAB Simulink model as shown in Figure 1 has been developed. The mathematical Equations (1) to (11) based on Liu \& Jordan's [17] method is designed as blocks and subsystems to create the model. The model also determines the solar radiation received on each tilt for different months. The main input parameters for these mathematical relations are representative days of the month, sunshine hours, cloud cover, and tilt angle [14]. For the proposed model, ' $\phi$ ' is assumed as $13.18^{\circ}$, the value of ' $\beta$ ' varies from $0^{\circ}$ to $90^{\circ}$, and ' $\gamma$ ' is assumed as $0^{\circ}$ (southfacing panels).

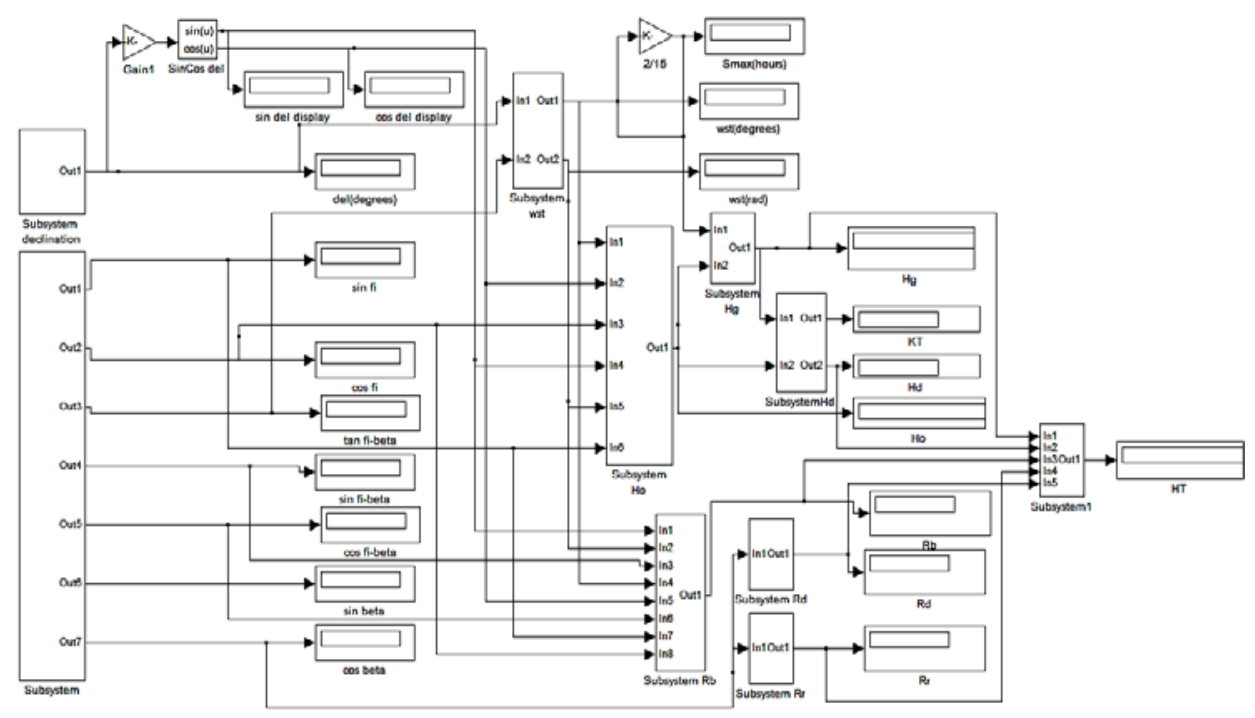

Fig. 1. MATLAB Simulink model for solar radiation calculation.

The experimental setup consists of a PV panel of 50W manufactured by Orb Energy as shown in Figure 2. The specification of the panel is given in Table 2. The panels are south faced without any shading effect to get maximum power. The supporting structure of the PV panel as shown in Figure 3 is specially designed in such a way that the angle can be varied 
easily with a protractor for reference. To find the optimal tilt for December to April the tilt angles were varied from $36^{\circ}$ to $0^{\circ}$ taking latitude $\left( \pm 15^{\circ}\right)$ of Nitte as reference. The reason behind choosing the month from December to April is because of the presence of monsoons during the rest of the season from May to November.

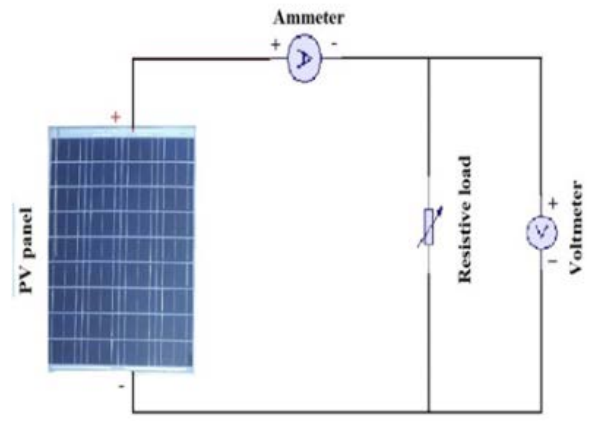

Fig. 2. Schematic representation of the experimental setup

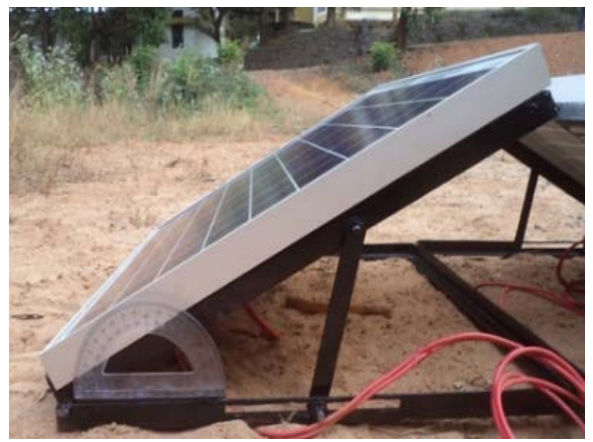

Fig. 3. Experimental setup and supporting structure of the PV panel with a protractor.

Table 2: PV panel specifications

\begin{tabular}{|l|l|}
\hline Parameters & Rating \\
\hline Nominal peak power (Pmpp) & $50 \mathrm{~W}$ \\
\hline Open circuit voltage (Voc) & $21.2 \mathrm{~V}$ \\
\hline Short circuit current (Isc) & $3.5 \mathrm{~A}$ \\
\hline Temperature of panel & $25^{\circ} \mathrm{C}$ \\
\hline Maximum power voltage (Vpm) & $16.5 \mathrm{~V}$ \\
\hline Maximum power current (Ipm) & $3.04 \mathrm{~A}$ \\
\hline Maximum system voltage & $540 \mathrm{~V}$ \\
\hline Radiation & $1000 \mathrm{~W} / \mathrm{m}^{2}$ \\
\hline Material & Polycrystalline \\
\hline Air mass & $\mathrm{AM} 1.5$ \\
\hline Dimension & $705 \times 655 \times 35 \mathrm{~mm}$ \\
\hline Weight & $\mathrm{Kg}$ \\
\hline
\end{tabular}

Reflectors are used to increase the power produced by the panel by focusing more radiation on it. Three types of reflectors such as mirror reflector (small and large), Aluminium sheet reflector, and stainless-steel sheet reflector as shown in Figure 4 are used in the experimentation. In the literature, two different methods are followed to find the optimum tilt angle. In the first method, the entire range of the tilt angle of the PV panel is varied in a 
day with predetermined angle steps and time duration [18]. This experimental method is carried out for several days and the average power of the PV panel is noted, through which optimal tilt angle is obtained.

In the second method, only single tilt angle is set for a day and that particular tilt angle is observed for the whole day [19]. The second method has been generally used and the same procedure is followed in the present experiment and parameters like voltage and current are measured on an hourly basis from 10 AM to 4 PM to determine the output power of the PV panel. Simultaneously solar irradiance, ambient temperature, and panel temperature are also noted. The optimal tilt angle for each month from December to April is determined. The influence of reflectors (Mirror, stainless steel, and aluminum sheet) on optimally tilted PV panel is also found using the same method.
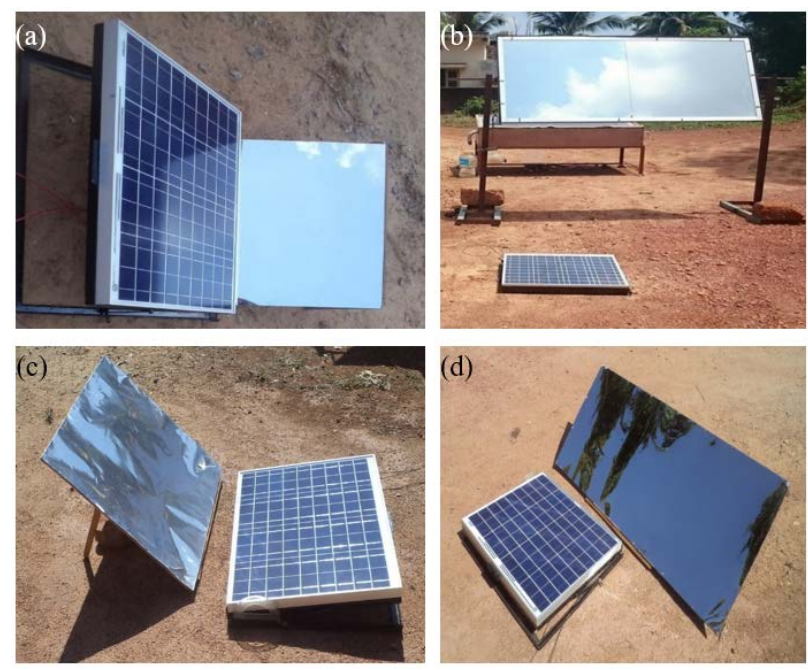

Fig. 4. Reflectors used in the current study. (a) small mirror reflector, (b) large mirror reflector, (c) aluminium sheet reflector, (d) stainless steel reflector.

\section{Results and Discussion}

The experiments were conducted for December, January, February, March, and April in the year 2019-20 at Nitte, India. The tilt was varied from $36^{\circ}$ to $0^{\circ}$ (taking latitude $\pm 15^{\circ}$ as reference) for these months to determine the tilt at which maximum power is obtained. The variation in the tilt angles obtained from the experimental study match the available literature for various locations.

\subsection{Effect of tilt angle on the output power of the PV panel for different months}

The plot of output power versus time for experimentally obtained optimum tilt angles is shown in Figure 5. The global radiation received is also plotted to understand its effect on the power generating capacity of the PV panel. As the experimental setup could be made ready only in late December, experimentation could be conducted only for limited days in December. The variation in peak and average power for December to April is plotted in Figure 6. It is observed that a tilt of $36^{\circ}$ produced both maximum and peak power in December. It is observed that the peak power is obtained at $2 \mathrm{pm}$ and the power graph is in inconsistent trend with the global radiation graph (Figures 5 and 6). It is observed from Figure 
5(a) that, though the solar radiation is almost consistent during several hours of the day, the power produced by the panel is not consistent as shown in Figure 5(b) and is high only around the noontime (12-2 pm). It is seen that a small drop in global radiation leads to a bigger drop in the power produced. This is because the PV panel will give optimal performance only at its designed specification as shown in Table 2. The drop in power during morning and evening is because of the lower intensity of global radiation (less than $1000 \mathrm{~W} / \mathrm{m}^{2}$ ). The experiments conducted by Kumar et al. [20] may be recalled here, wherein, unlike places in Rajasthan which receive radiation in the range of $1000-1270 \mathrm{~W} / \mathrm{m}^{2}$, a place like Nitte receives lesser radiation in the range of $900 \mathrm{~W} / \mathrm{m}^{2}$. A large drop in power is observed for any drop in radiation below $1000 \mathrm{~W} / \mathrm{m}^{2}$. Hence, for radiation in this range, a drop in power is more when compared to the standard values. In January, it is observed that $33^{\circ}$ tilt produces maximum, average, and peak power. The variation in power is mainly due to the cloudy conditions and the lower amount of solar radiation received. It is observed that $22^{\circ}$ tilt produces average maximum power output in a day whereas peak power is obtained at $24^{\circ}$ in February.

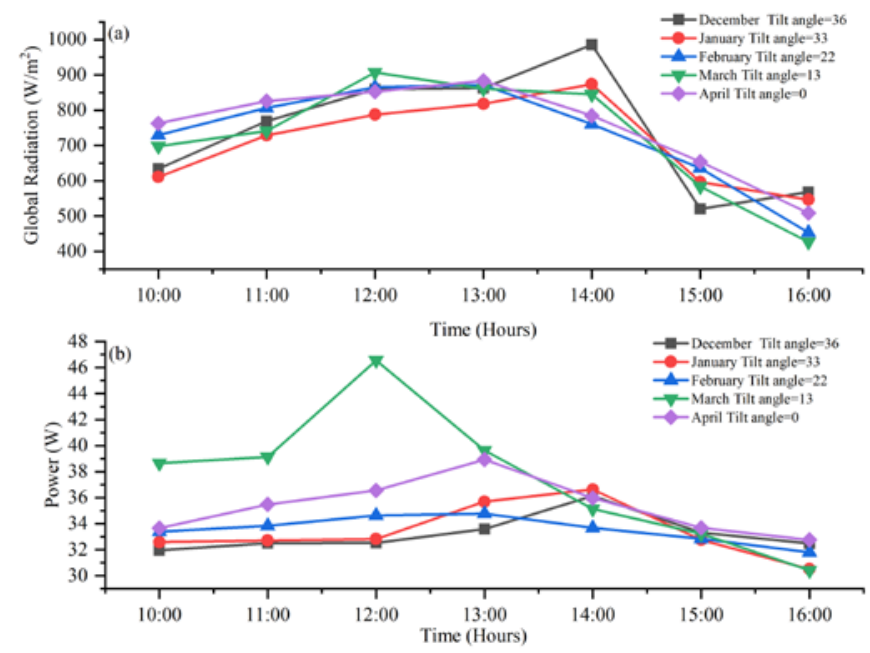

Fig. 5.: Results obtained by the experimental setup, (a) global radiation for the test period, (b) power output for various tilt angles at different time intervals.

When the tilt angle is $22^{\circ}$ in a day in February, it is observed that the duration of peak power is advanced by a few hours when compared to the previous months due to change in the path of the sun, because of seasonal changes of declination angle. The variation in power is mainly due to the cloudy conditions that were present during the day. The maximum and peak power is produced for the tilt angle of $13^{\circ}$, and $0^{\circ}$ for March and April respectively. In March, the power variation is mainly because of diffused radiation in the early and later part of the day. It is observed that the peak power is advanced further at 12 pm (Figure 5 (a)) indicating the sun is directly overhead during summer and produces maximum power much earlier as compared to winter. The tilt angle of $13^{\circ}$ is equal to the latitude of Nitte and agrees with the certain research work where a tilt angle equal to latitude produces maximum power [21-24]. For April, it is observed that the power production varies depending on the variation in solar radiation and the peak power is obtained around $1 \mathrm{pm}$. The duration of peak power production is varied because of the change in the declination angle of the sun for summer when the sun is directly overhead. Though the actual process of measuring dust deposition on the PV panel is not carried out, it is observed that lower tilt angles require frequent cleaning of dust as compared to higher tilt angles [19]. 

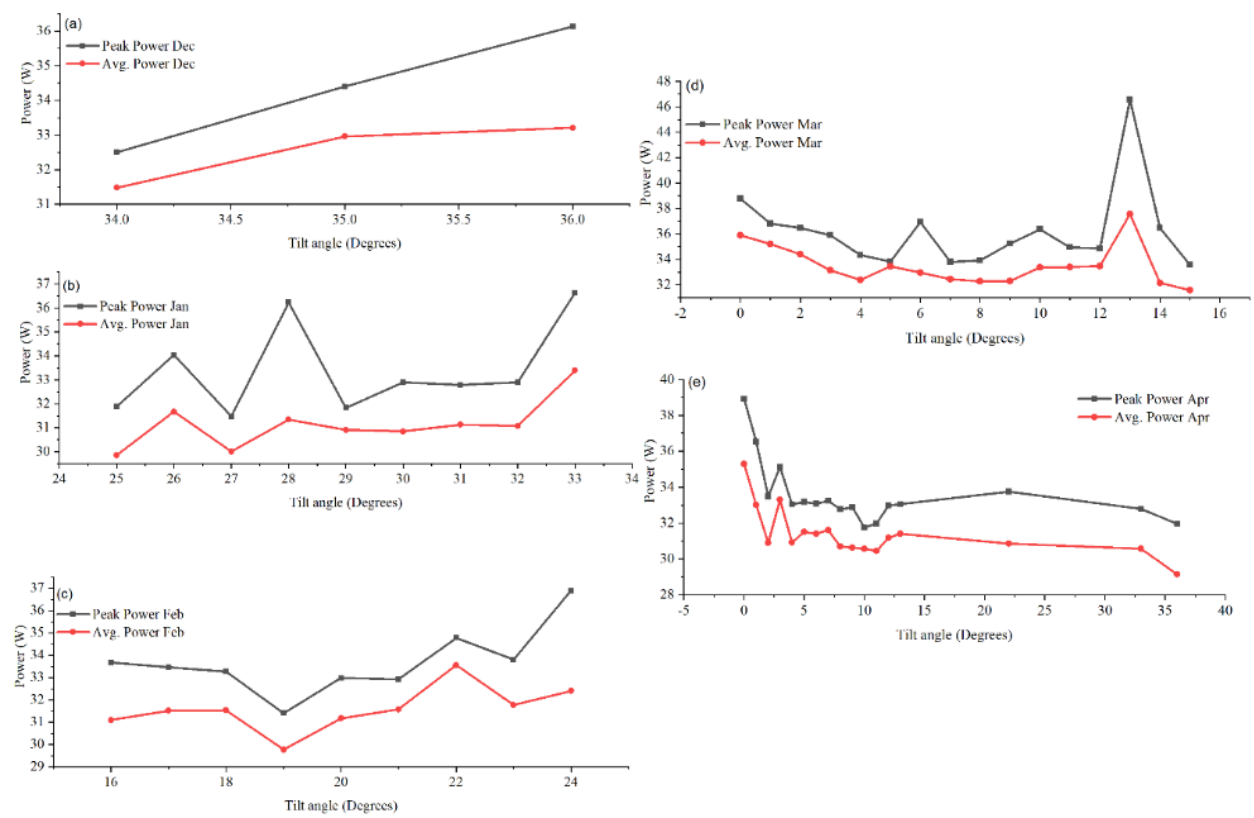

Fig. 6. Variation in peak and average power with respect to various tilt angles from December to March.

A decreasing pattern of tilt angles is observed for the first few months of the year similar to the universal trend [25-26]. There is hardly a $2 \%$ variation in peak and average power over the five months provided tilt angles are appropriately adjusted. If the tilt angles are not changed monthly, there would be roughly $10 \%$ or more loss of power. In the literature, the experimental results have witnessed higher tilt angles for winter while lower tilt angles for summer [24, 27]. It is observed from Figure 7 that by maintaining a monthly optimum tilt angle, consistently maximum power is obtained for all the months under investigation. This indicates that determining the optimal tilt is important for every location before installation.

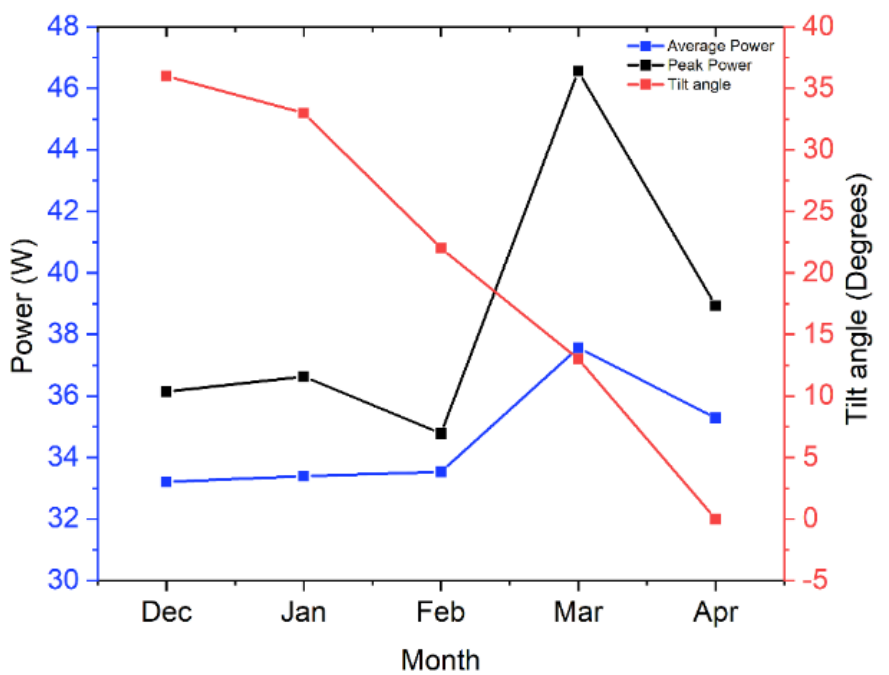

Fig. 7. Variation of Power and the pattern of tilt angle for December to April. 


\subsection{Mathematical method}

The mathematical model developed using MATLAB Simulink is discussed in the methodology section. The main input parameters for this model are the latitude, tilt angle, and sunshine hours [14]. The representative days for each month are entered in the model and the tilt angle is varied from $0^{\circ}$ to $90^{\circ}$ [25]. It is observed from Figure 8 that negative tilt angles are obtained during May, June, and July. Negative tilt represents that the panels are facing away from the equator (North facing). The negative tilt is mainly because, the sun crosses the latitude of location and moves towards the north till it reaches maximum declination in July. Later, the pattern of tilt angle increases indicating that the sun is moving towards the equator from maximum declination. A similar case was found in literature, but the work does not justify for PV panels with fixed type arrangement [28]. Hence generally when a negative tilt angle is obtained, one can choose $0^{\circ}$ tilt (horizontal surface), due to constraints related to mounting structures and the marginal benefit of an increase in output power.

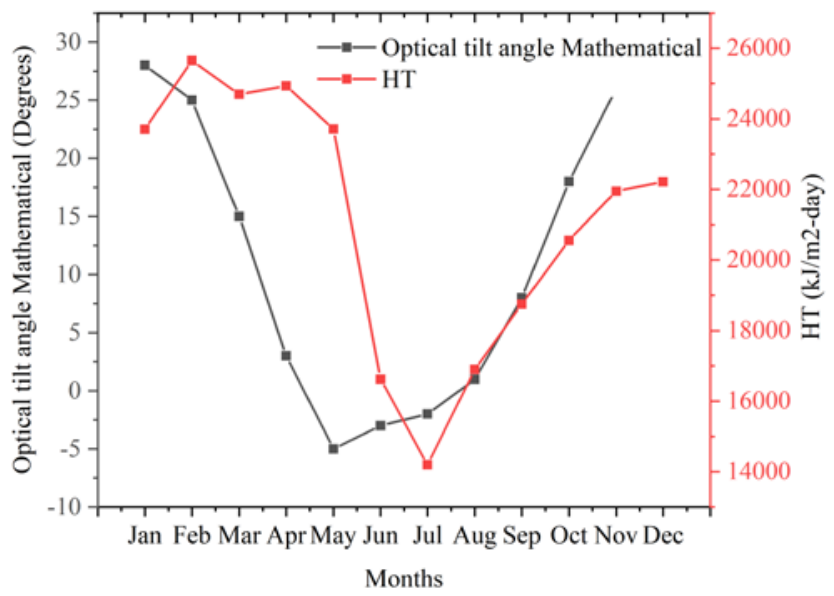

Fig. 8. Variation of Tilt and daily radiation falling on a tilted surface for the entire year.

\subsection{Comparison of mathematical modelling with the experimental method}

The tilt angle obtained for each month from experimental and mathematical methods is almost convincing for all the months with marginal variations. The variation may be due to limitations of the model to include the effect of all the environmental parameters. The tilt angle could be determined experimentally only for 5 months of the year, whereas, using the mathematical model it was determined for the entire year. It is observed that the pattern of tilt angles obtained from both the methods shows the same trend which is as per the established universal trend [25] with a marginal difference for the first few months. The plot of the experimental method can be extrapolated for the entire year as seen in Figure 9. A decreasing pattern of tilt angles is observed for the first half of the year, because of the movement of the sun from its lowest path towards the latitude of the location. It can be observed that the optimal tilt angle of PV panels obtained from the mathematical model does not take into consideration environmental effects, losses in the wires, and variation in load conditions and hence it differs from experimentally obtained values. 


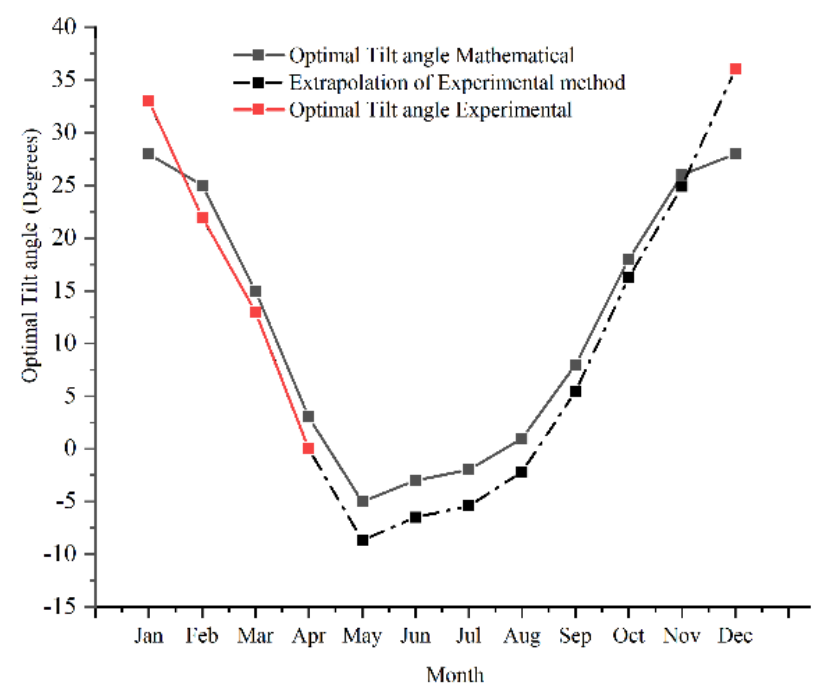

Fig. 9. Extrapolation of tilt angle obtained by mathematical and experimental methods.

\subsection{Effect of reflectors on output power}

To realize the rated power, reflectors are used to focus additional radiation on the PV panel. This section discusses the study on the effect of different types and arrangements of reflectors for PV panels. Figure 10 represents the variation in the power of the PV panel with the use of different types of reflectors for April. It can be observed from the Figure 10 that the use of a mirror produces maximum power when compared to a stainless-steel sheet and aluminum. The size of the reflector also affects the output power produced. It can be observed from Figure 10, power obtained by large still mirror as the reflector is uniform and high throughout the day while power produced by a small mirror is nonuniform and lower than the former. Since the size of the small mirror was lesser than that of the PV panel, it had to be focused frequently on the panel. Hence the results cannot be compared in absolute terms with the results of the larger mirror. But when focused properly, the small mirror produces more power than the larger mirror. Therefore, to obtain maximum uniform power throughout the day, a reflector larger than the panel must be used.

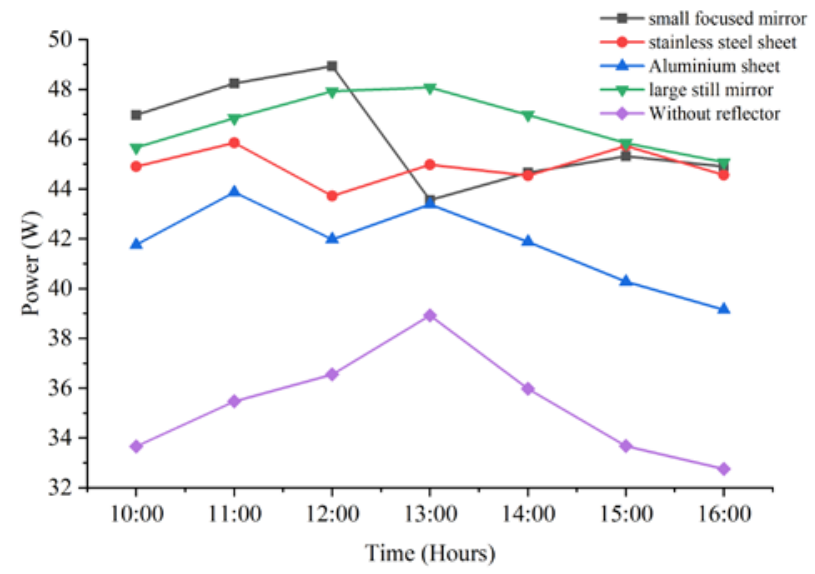

Fig. 10.: Effect of reflectors on optimal tilt for April 


\section{Conclusion}

The current investigation was focused on determining the optimal tilt angle for Nitte, India for generating maximum power for PV panels. The study has been carried out using both experimental and mathematical models. The experimental study is carried out for five months of the year from December to April due to academic and climatic constraints. However, it is possible to predict the tilt angles for the remaining months using a mathematical model after verification and validation with the available experimental data. The findings of the study are as follows:

1. It is found that the tilt angle for each month of the year is different, which indicates that determining the optimal tilt is important, otherwise, there will be a loss of 10$20 \%$ output power. From the experimental study, it was found that $0^{\circ}$ tilt angle for April, $13^{\circ}$ tilt angle for March, $22^{\circ}$ tilt for February, $33^{\circ}$ tilt for January, and $36^{\circ}$ tilt for December produces a maximum power output.

2. A place like Nitte, India which is on the coastal belt of Karnataka, India receives lesser global radiation in the range of $900 \mathrm{~W} / \mathrm{m}^{2}$, whereas the specified radiation for maximum power for $\mathrm{PV}$ panel is $1000 \mathrm{~W} / \mathrm{m}^{2}$. It is found that the designed power rating could not be realized because of the lesser radiation than the specified level.

3. The orientation of the panel overcomes the problem of lower global radiation. The power drop was found to be in the range of $9-35 \%$ on a given day. However, it may not be economically viable to orient the panel throughout the day using a tracking mechanism.

4. The simulation of the mathematical model for Nitte location shows that the model can be used for predicting the tilt angle reasonably well. However, further work needs to be carried out to match it exactly with the experimental work by considering all environmental parameters.

5. Environmental conditions like, temperature and humidity have a marginal effect on the output of solar panels as compared to the effect of global radiation. On the other hand, cloudy conditions have a direct impact on global radiation which in turn affects power production.

6. It is found that reflectors have a good impact on the performance of the PV panel and power could be increased up to $24 \%$. A Smaller reflector, when focused properly is more effective compared to a larger still reflector. However, a larger still reflector, without focusing and with a proper fixed orientation, can obtain maximum uniform power throughout the day.

7. The preliminary investigations in the present study did not indicate any significant effect on panel temperature as compared to global radiation.

8. The rated power of the panel could not be achieved for Nitte, India, due to lesser global radiation received below $1000 \mathrm{~W} / \mathrm{m}^{2}$. Optimum tilt angle, panel orientation, and use of reflectors can aid in achieving the rated power. However, an optimum tilt angle with a reflector is an ideal solution for achieving the rated power economically. From the investigation we can conclude that it is possible to predict the optimal tilt angle of any location using mathematical model used in the study. The existence of these simple models and MATLAB software have very positive impact on obtaining optimal tilt angle for a location to setup PV panels.

\section{References}

1. J. Yan, Y. Yang, P. Elia Campana, J. He, Nat. Energy. 4, 709 (2019).

2. G. Li, S. Shittu, T.M.O. Diallo, M. Yu, X. Zhao, J. Ji, Energy. 158, 41 (2018). 
3. H.P. Garg, J. Prakash, Solar Energy Fundamentals and Application, (McGraw, New Delhi, 1977).

4. J. Kern, I. Harris, Sol. Energy. 17, 97 (1975).

5. A. Ullah, H. Imran, Z. Maqsood, N.Z. Butt, Renew. Energy. 139, 830 (2019).

6. H.Z.M. Guo, S. Gao, T. Chen, J. Xiao, L. Cheng, Z. Wei, G. Sun, Appl. Sci. 7, 1028 (2017).

7. T.O. Kaddoura, M.A.M. Ramli, Y.A. Al-Turki, Renew. Sust. Energy. Rev. 65, 626 (2016).

8. J. Appelbaum, Renew. Energy. 85, 338 (2016).

9. D. Jain, M. Lalwani, Int. J. Renew. Energy Res. 7, 1053 (2017).

10. H. Tabor, Sol. Energy, 2, 27 (1958).

11. P. Malik, S.S. Chandel, Renew. Energy. 154, 966 (2020).

12. A.E. Kabeel, M. Abdelgaied, J. Clean. Prod. 224, 40 (2019).

13. A. Chel, G.N. Tiwari, A. Chandra, Energy Build. 41, 1172 (2009).

14. S.P. Sukhatme, J. Nayak, Solar Energy: Principles of thermal collection and storage, (McGraw, India, 2008).

15. T. Jenkins, G. Bolivar-Mendoza, Solar Time, Angles, and Irradiance Calculator: User Manual, (NM State University, New Mexico, 2014).

16. S.A. Klein, Sol. Energy., 19, 325 (1977).

17. B.Y. Liu, R.C. Jordan, Sol. Energy., 4, 1 (1960).

18. K. Ajao, R. Ambali, M. Mahmoud, JESTR, 6, 87 (2013).

19. A. Rouholamini, H. Pourgharibshahi, R. Fadaeinedjad, G. Moschopoulos, $26^{\text {th }}$ IEEE Canad. Conf. Elec. Comp. Eng. 1, 1 (2013).

20. S. Kumar, P. Chaurasia, H.K. Singh, Int. J. Sci. Res., 3, 195 (2014).

21. A. Mraoui, M. Khelif, B. Benyoucef, $5^{\text {th }}$ Int. Renew. Energy Cong. (IREC). 1, 1 (2014).

22. T. Khatib, A. Mohamed, K. Sopian, IEEE Int. Pow. Eng. Optimiz. Conf. 7 (2012).

23. Y. Chang, Y. Lieh-Dai, Int. Conf. Renew. Energy Res. Appl. (ICRERA). 1 (2012).

24. M. Lakhdar, L.D. Korichi, J. Electr. Eng. 1, 13 (2020).

25. M. Jamil Ahmad, G. N Tiwari, TOREJ. 1, 2 (2009).

26. A. Chandrakar, Y. Tiwari, Int. J. adv. res. technol., 3, 145 (2013).

27. T. Pavlović, Z. Pavlović, L. Pantić, L. Kostić, Contemp. Mater., 2, 151 (2010).

28. I. Daut, M. Irwanto, Y.M. Irwan, N. Gomesh, N.S. Ahmad, Int. Conf. Elec. Contr.Comp. Eng. (InECCE), 1, 445 (2011). 